\title{
Perioperative management of uncorrected D-TGA with brain abscess: $A$ case report
}

\begin{abstract}
Transposition of Great Arteries (TGA) is the most common cyanotic congenital heart defect in neonate, where aorta arises from right ventricle and pulmonary artery from left ventricle. Major complications in such patients are haemodynamic instability, cyanotic spells, coagulation defects, electrolyte \& acid base imbalance, seizure and sudden cardiac arrest which owe to the high mortality rate. Patients with cyanotic heart disease are very prone to develop frequent brain abscess. We report successful management of a patient having cyanotic heart disease (Uncorrected D-TGA) presented with multiple episodes of seizures, high grade fever and severe respiratory distress. Initially the patient was managed in intensive care unit with ventilatory support and antibiotic coverage. After stabilization, CT brain was planned which revealed ring enhancing lesion in left temporal lobe causing mild mass effect and moderate surrounding edema with abnormal leptomeningeal enhancement (S/O: Abscess? Tubercular?). After an expert neurosurgical opinion, the patient was transferred to operation theatre and planned for drainage of abscess. Evacuation was successfully done without any abnormal intraoperative event. Then the patient was shifted to ICU and gradually weaned from ventilator and extubated.
\end{abstract}

Keywords: congenital cyanotic heart disease, brain abscess, general anaesthesia
Volume 7 Issue I - 2017

\author{
Suman Saurabh,' Kumar Neeraj,' Singh \\ Kumar Akhilesh, ${ }^{2}$ Kumar Amarjeet, ${ }^{2}$ MWR \\ Subhdeep' \\ 'Department of Anaesthesiology and Critical Care, Senior \\ Resident, Institute of Medical Sciences, Banaras Hindu University, \\ India \\ ${ }^{2}$ Department of Anaesthesiology and Critical Care, Senior \\ Resident, All India Institute of Medical Sciences, India
}

\begin{abstract}
Correspondence: Neeraj Kumar, Department of Anaesthesiology and Critical Care, Senior Resident, Institute of Medical Sciences, Banaras Hindu University, Sushruta Hostel, Room no. I 73, Trauma Center, BHU,Varanasi, India, Tel +918505864856, Email Neeraj.jnmch@gmail.com
\end{abstract}

Received: January 10,2016 | Published: January 18, 2017

\section{Introduction}

Congenital heart defects may present as mild lesions such as minor endocardial cushion defects or moderate to severe defects arising from morphologic anomalies of the myocardium and cardiac vasculature. The incidence rate of moderate to severe congenital heart disease was estimated to range from 6 to 19 per 1,000 live births, with an overall rate of 75 per 1,000 live births. ${ }^{1}$ Brain abscess is an uncommon but life threatening intracranial infection characterized by purulence and inflammation in one or more localized areas within the brain parenchyma. In TGA due to non-mixing, the two circuits remain separate, without any filtration at pulmonary level so they are very prone to infection and abscess formation leading to death. In presence of congenital defect, there is mixing of blood which leads to hypoxia and consequently polycythemia and hyperviscosity. The latter results in sluggish blood flow in cerebral microcirculation, micro thrombi formation and direct entry of organisms, emboli, infected seed to cerebral circulation forming cerebral abscess till date on expansive search of the literature it was found that only a few reports of patients with unrepaired cardiac lesions undergoing anesthesia for noncardiac surgery.

\section{Case report}

A nine year old, male child presented in the emergency with 2-3 episodes of seizure, high grade fever and respiratory distress since 15 days. Seizure were of generalized tonic clonic type and was associated with drooling of saliva, uprolling of eyeball, spontaneous micturition of urine and cyanosed limb and face. Immediately intravenous lorazepam $2 \mathrm{mg}$ were given in bolus dose and intubated with PVC cuffed endotracheal tube $6 \mathrm{~mm}$ ID and controlled mode of ventilation were started. This was accomplished by rapid sequence intubation technique using inj thiopentone $5 \mathrm{mg} / \mathrm{kg}$ and inj rocuronium $1 \mathrm{mg} / \mathrm{kg}$. Then patient was shifted to intensive care unit, where bedside $2 \mathrm{D}$-echocardiography and chest roentogram were done. The 2-D echocardiography revealed atrioventricular and ventriculo atrial concordance, D-TGA, large patent foramen ovale, right to left shunt, moderate pulmonary artery hypertension and the chest roentogram revealed egg on side appearance with presence of infiltrates in the Right Lower Lobe. Routine investigations, blood culture, tracheal tube culture and serum procalcitonin levels were sent. Antibiotic coverage were started in view of suspected aspiration during seizure and a non-contrast CT scan of brain were ordered following seizure episode which revealed ring enhancing lesion in left temporal lobe causing mild mass effect and moderate surrounding edema with abnormal leptomeningeal enhancement (S/O: Abscess? Tubercular?). Laboratory investigations showed $\mathrm{Hb}-22.4 \mathrm{~g} \%$ with Hct-64.9\%, platelets counts- $142,000 / \mathrm{mm} 3$, and Total leucocyte count-14,600/ $\mathrm{mm} 3$ with normal liver and renal function tests.

Arterial blood gas revealed PO2- $52.4 \mathrm{mmHg}$ and $\mathrm{SO} 2-78 \%$. On above findings neurosurgeon opinion were taken and drainage of brain abscess were planned under general anaesthesia. After arrival in the operation theatre all ASA standard monitors were attached and baseline parameters were recorded. Heart rate was $124 / \mathrm{min}$, blood pressure was $92 / 54 \mathrm{mmHg}$, oxygen saturation was $88 \%$ and temperature was 39 degree Celsius. An inline air filter was added to the tubing, and all bolus IV medications were administered through it. The antibiotic prophylaxis were achieved with slow IV administration of ampicillin $500 \mathrm{mg}$, and amikacin $250 \mathrm{mg}$, before commencement of the anesthetic induction and airway manipulation. Intermittent inj fentanyl $2 \mu \mathrm{g} / \mathrm{kg}$ and inj vecuronium $0.1 \mathrm{mg} / \mathrm{kg}$ were given to facilitate analgesia and neuromuscular blockade Muscle relaxants such as vecuronium and rocuronium have high autonomic margins of safety. ${ }^{2,3}$ Anaesthesia was maintained by $\mathrm{O}_{2}(50 \%)$ with Air (50\%) and sevoflurane. With regard to the volatile anesthetic agents, it is known that they have little overall effect on PVR. ${ }^{2}$

However, use of nitrous oxide $\left(\mathrm{N}_{2} \mathrm{O}\right)$ has been shown to increase PVR. ${ }^{2,45}$ Therefore, this agent were avoided in our patient. Central venous catheterization in the right subclavian vein and an arterial catheter in the dorsalis pedis artery were inserted to monitor the CVP 
and Invasive blood pressure respectively. Episodes of hypotension and decrease in saturation less than $80 \%$ were managed by bolus doses of Phenylephrine. As its use will lead to increase in SVR from direct $\alpha$-stimulation and vasoconstriction diminished the occurrence of right-to-left shunting. ${ }^{6}$ Intraoperative monitoring were done by electrocardiogram, pulse oximetry, ETCO2, noninvasive blood pressure (NIBP), arterial blood pressure (IBP), central venous pressure (CVP), and arterial blood gases. Intraoperative ringer lactate at a rate of $15 \mathrm{ml} / \mathrm{kg} / \mathrm{hr}$ were used to maintain CVP $7-10 \mathrm{~cm}$ of $\mathrm{H} 2 \mathrm{O}$ and inj mannitol $0.5 \mathrm{~g} / \mathrm{kg}$ were given to reduce cerebral oedema. The surgery lasted for about two hours with minimal blood loss and throughout the procedure the vitals were maintained stable to minimize any episode of cyanotic spell or hypoxia. At the end of surgery, residual neuromuscular blockade was reversed and after awakening the patient trachea were extubated. The patient were shifted to neurosurgical ICU for further monitoring. Inj paracetamol $15 \mathrm{mg} / \mathrm{kg} 8$ hourly was used for postoperative analgesia.

\section{Discussion}

Patients with congenital cyanotic heart disease are very prone to develop a brain abscess. It is more common in children than adults. In such patients there is a right-to-left shunt which will bypass the pulmonary circulation and hence bacteria in the bloodstream are not filtered through the pulmonary circulation. Anaesthetic considerations related to TGA with brain abscess are following: maintenance of intravascular volume and preload and avoidance of precursors

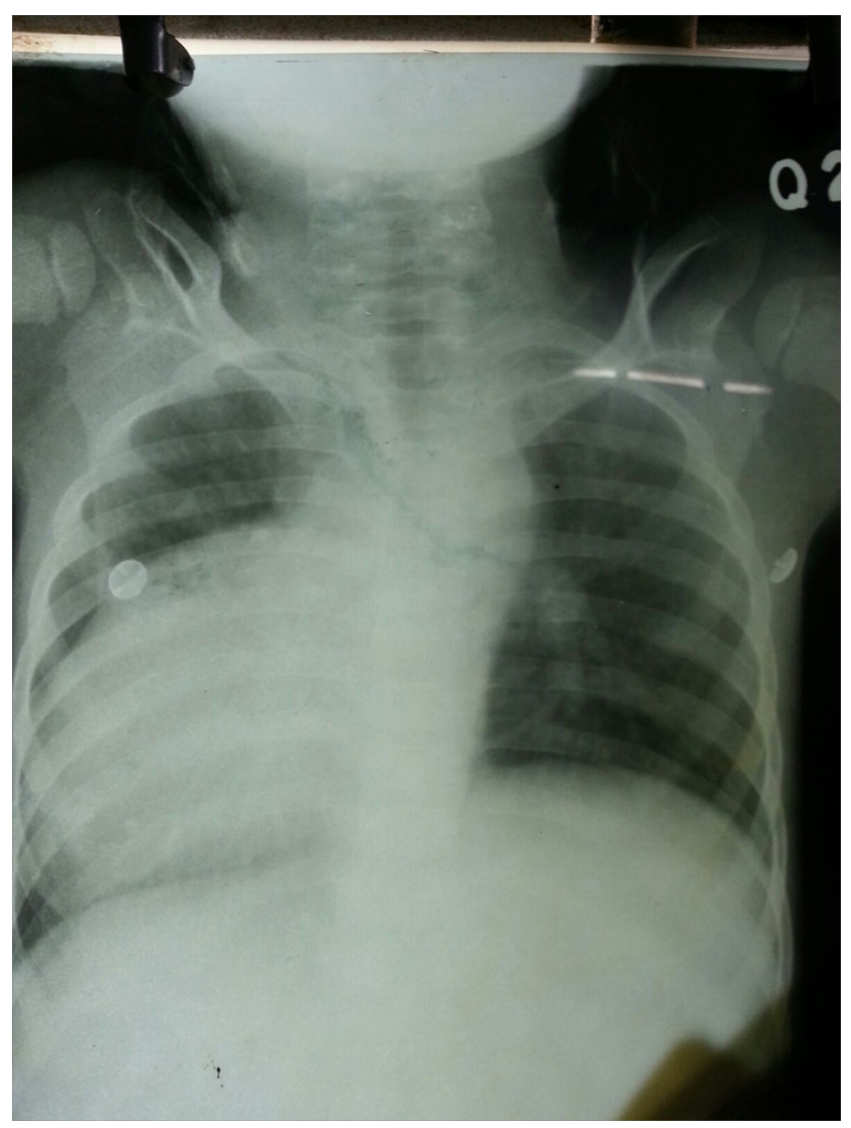

\section{Conclusion}

Brain abscess is a known complication in patients with cyanotic congenital heart disease, which must be diagnosed early and treated to acidosis such as hypothermia, hypercarbia, and hypotension. Minimization of intracardiac shunting were typically achieved via avoidance of decrease in systemic vascular resistance and increase in pulmonary vascular resistance (PVR). These unfiltered bacteria may further lead to development of brain abscess. These patients are exposed to chronic tissue hypoxia which causes increased production of erythropoietin and further polycythemia, hyper viscosity develops that leads to thromboembolism and stroke. Pulmonary hypertensive crisis constitutes a major risk for adult patients with congenital heart disease, predisposing them to a significantly increased.

Incidence of preoperative morbidity and mortality. ${ }^{7,8}$ Suggested modalities for the treatment of this occurrence are hyperventilation with an inspired oxygen concentration (FiO2) of 1.0, judicious administration of volume, use of vasoconstrictors to elevate SVR, and control of wide variations of the heart rate. ${ }^{6-8}$ Hence judicious preoperative hydration is very necessary. Till date there is no conclusive anaesthetic plan for TGA with brain abscess. Preoperatively, an understanding of the patient's underlying pathophysiology, coupled with knowledge of the effects of anesthesia on the anomalous myocardium, is crucial. Although extensive preoperative evaluations by the patient's intensivist, cardiologist, and cardiac surgeon are preferable, they may not be readily available, as were the case with this patient. Careful review of the patient's preoperative medication profile, with attention to potential anesthetic interactions, must be considered (Figure $1 \& 2$ ).

aggressively. A carefully administered GA with controlled ventilation, maintaining cardiac output, normal sinus rhythm and keeping PVR relatively lower than SVR along with lax brain is usually recommended. We should avoid even a small amount of intravascular air and give adequate postoperative analgesia. So a proper and titrated administration of sedatives and anesthetic agents, control of wide variations in heart rate, avoidance of volume overload and subsequent congestive heart failure, and avoidance of IV air embolization is also recommended. With careful planning by the surgical and anesthesia care team, adult patients with congenital heart disease may be successfully anesthetized for non-cardiac surgery without incident.

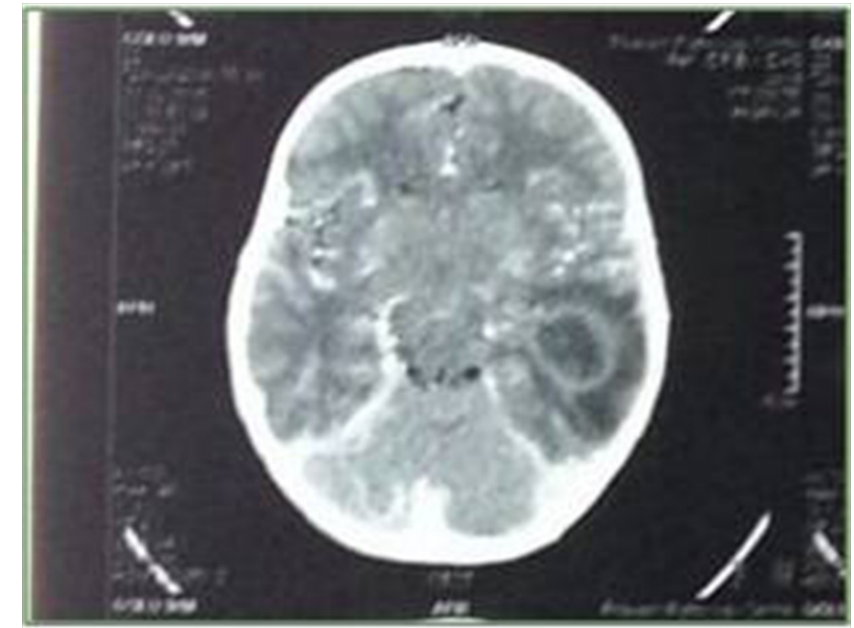

\section{Conflicts of interest}

There is no conflict of interest.

\section{Acknowledgements}

None. 


\section{Funding}

None.

\section{References}

1. Hoffman JI, Kaplan S. The incidence of congenital heart disease. J Am Coll Cardiol. 2002;39(12):1890-1900.

2. Stoelting RK, Hillier SC. Pharmacology and Physiology in Anesthetic Practice. (4th edn), Lippincott Williams \& Wilkins, Philadephia, USA. 2006:54,106-110,165-166,172,233,235,238.

3. Andropoulos DB. Anesthetic agents and their cardiovascular effects. In: Andropoulos DB, Stayer SA, Russell I, Mossad EB, eds. Anesthesia for Congenital Heart Disease. (2nd edn), Wiley-Blackwell, West Sussex, UK. 2010:80,83,85,89.

4. Mossad EB, Joglar J. Preoperative evaluation and preparation. In:
Andropoulos DB, Stayer SA, Russell I, Mossad EB, eds. Anesthesia for Congenital Heart Disease. (2nd edn), Wiley-Blackwell, West Sussex, UK. 2010:228.

5. Andrews JD. Laparoscopic cholecystectomy for the adult with unrepaired tetralogy of Fallot: a case report. AANA J. 1999;67(1):67-71.

6. Levin SK, Arslan-Carlon V. Tetralogy of Fallot. In: Yao FSF, Ed. Yao \& Artusio's Anesthesiology: Problem-Oriented Patient Management. (5th edn), Lippincott Williams \& Wilkins, Philadelphia, USA. 2003:242244.

7. Cannesson M, Collange V, Lehot JJ. Anesthesia in adult patients with congenital heart disease. Curr Opin Anaesthiol. 2009;22(1):88-94.

8. Cannesson M, Earing MG, Collange V, et al. Anesthesia for noncardiac surgery in adults with congenital heart disease. Anesthesiology. 2009;111(2):432-440. 